\title{
Impact of Family Function on Mental Health Problems of College Students in China During COVID-19 Pandemic and Moderating Role of Coping Style: A Longitudinal Study
}

Lili Liu

Southern Medical University

Jianbin Chen

Southern Medical University

Shunwei Liang

Southern Medical University

Wenwen Yang

Yunnan University of Chinese Medicine

Xiaodan Peng

Southern Medical University

Chengcheng Cai

Southern Medical University

Andi Huang

Southern Medical University

Xiayong Wang

Southern Medical University

Jingbo Zhao ( $\sim$ mingtian@smu.edu.cn )

Southern Medical University

\section{Research Article}

Keywords: Young adults, COVID-19, family functioning, coping styles, depressive symptoms, anxiety, longitudinal study

Posted Date: October 12th, 2022

DOI: https://doi.org/10.21203/rs.3.rs-878815/v2

License: (c) (i) This work is licensed under a Creative Commons Attribution 4.0 International License. Read Full License 


\section{Abstract \\ Background}

During the COVID-19 pandemic, college students were required to stay at home and maintain social distancing the entire spring semester of 2020. There is little research on how family function influenced mental health problems and how coping styles moderated the relationship between family function and mental health problems among college students during their stay-at-home period.

\section{Methods}

We carried out four evaluations between February and October 2020 through an online survey. A total of 13,462 college students (age $=16-29$ years) participated. Family function, coping styles, depression symptoms, and anxiety symptoms were studied. To evaluate the associations between variables, a generalized estimating equation was used.

\section{Results}

Findings indicate that the incidence rates of depression rose during stay-at-home period from $33.87 \%, 95 \% \mathrm{Cl}(29.88 \%$, $38.10 \%)$ to $40.08 \% 95 \% \mathrm{Cl}(35.76 \%, 44.55 \%)$ after schools reopened, $\chi^{2}=193.68, p<0.001$. The incidence rates of anxiety rose from $17.45 \%, 95 \% \mathrm{Cl}(14.59 \%, 20.73 \%)$ to $26.53 \%, 95 \% \mathrm{Cl}(16.94 \%, 23.67 \%)$ through the entire period, $\chi^{2}=195.74, p<0.001$. The incidence rate of depression and anxiety for different family function groups varied at different time points, the interaction effect was significant $(\chi 2=52.97, p<0.001$ and $\chi 2=51.25, p<0.001$, respectively). The incidence rate of depression and anxiety for different family function groups with different coping styles also varied at different time points, the interaction effect was likewise significant $(\chi 2=862.09, p<0.001$ and $\chi 2=583.29, p<0.001$, respectively).

\section{Conclusions}

These findings shed light on how family function intersected with coping styles to influence the mental health problems of college students during and after the stay-at-home period of COVID-19. These findings highlight the importance of paying special attention to college students' family function and promoting appropriate coping strategies during and after COVID-19.

\section{Introduction}

It is now clearly evident that COVID-19 pandemic has had psychological and social impact worldwide, and studies have indicated that mental health problems had become a big global issue[1-3]. To prevent the rapid spread of COVID-19, in February 2020 the Chinese government ordered a nationwide closure of all educational institutions and the Ministry of Education suggested "suspending classes without suspending learning." Students across the country were required to stay at home and study online [4]. University campus life and learning environment play a crucial role in students' psychological development, their peer relationship, and autonomy [5]. The results of a nationwide survey in China show that COVID-19 pandemic has brought about a high degree of psychological stress to general population, especially younger generation[4-8].

Large-scale health disasters intensify not only the psychological stressors but also the basic human need to feel safe, connected, calm, useful, and hopeful [7]. Previous research studying the impact of COVID-19 on an individual's mental health mainly focused on the epidemiology of depression, anxiety, sleeping problems, suicidal ideation, and PTSD symptoms [9-11], and the mental health of infected people and vulnerable populations such as elderly, children and healthcare workers [12-14]. However, there is a lack of research on long-term mixed effects of family and coping strategies that affected mental health problems during COVID-19 pandemic. 
Family is one of the most prominent factors that impact mental health, and impaired family environments contribute to the risk for mental health problems (MHP) among family members [15-17]. A nationwide strict lockdown during the pandemic meant long-term home isolation. The negative psychological effects of social isolation are obvious, and a lack of sufficient personal space in the family may contribute to frequent parent-child conflicts and a surge in family pressure or even family violence [18]. Family functioning is defined as the extent to which a family performs as a unit to cope with stressors [19]. Previous studies have shown that family function is positively correlated with mental health before and during the pandemic [20-22], and children growing up in an environment with high family functioning have low level of MHP[22].

Under the impact of both COVID-19 pandemic and family pressure, an individual's coping style plays a significant role between pressure and mental health $[23,24]$. Coping style refers to the specific efforts, both behavioral and psychological, that people employ to master, tolerate, reduce, or minimize stressful events [25]. According to the integrated model of coping process proposed by N Ntoumanis, J Edmunds and JL Duda [26], N Ntoumanis, J Edmunds and JL Duda [27], coping strategies are the result of stress appraisals, which can be influenced by social context and psychological needs.[29][30]. When an individual faces a stressful situation, different appraisals occur depending upon the evaluation of the stressor. RS Lazarus and S Folkman [28] have identified four different types of appraisals as harm-loss, threat, challenge, and benign. Harm-loss appraisal refers to a damage that has already been done and is more likely to induce an emotionally focused passive coping style. Threat appraisal refers to a potential for harm or loss, and because the damage is yet to come, an individual may have a strong response that tries all kinds of strategies to cope. Challenge appraisal refers to an opportunity for personal growth, which easily leads one to take an active coping style and focus at problem itself. Benign appraisal refers to a situation when an individual believes there is no threat, takes no further appraisal, and gives a weak response [26, 27]. Recent cross-sectional studies have indicated that maladaptive coping strategies such as passive coping emerged as a risk factor of mental health during the pandemic $[24,29,30]$, and active coping strategies, such as spiritual skills, can be a resource to address mental health issues[30, 31].

Although previous studies have used retrospective designs with respect to possible risk factors [32], little research has been done to understand the effect of interaction between social context and self-determined variable on the mental health of college students during the quarantine period. This study presents the results of a longitudinal research to comprehensively describe changes in the mental health states of college students with different family function and different coping styles from the beginning until the end of the quarantine period. We hypothesis a moderator model, family function would be negatively associated with MHP (hypothesis 1), and the influence will be weakened after schools reopened (hypothesis 2). Different coping styles would moderate the relation between family function and MHP during different times (hypothesis 3 ). The objective of this study was to assess how the main social context (family) and self-determined variable (coping style) together influence the mental health problems of college students during and after the stay-at-home period.

\section{Methods}

\subsection{Study design and participants}

This longitudinal prospective observational study was conducted on a large sample of college students from 22 colleges and universities in the Guangdong Province of China. There are 160 colleges and universities in Guangdong Province of China, including 67 undergraduate universities and 93 three-year colleges, we used the representative sampling method to choose the sample schools, which contain 10 undergraduate universities and 12 three-year colleges. The study was carried out in four survey periods: February 3-10, 2020 (T1); March 24 to April 3, 2020 (T2); June 1-15, 2020 (T3); and September 10 to October 17, 2020 (T4).

At the first survey, students had vacations and all colleges were closed. During the second and third survey, students were still at home but taking online courses. At the fourth survey, all colleges were reopened, students were back at school, so it was conducted at each college, using the same means as for the first three surveys. 
A total of 164,101 students (response rate $37.3 \%$, valid questionnaire: $88.3 \%$ ) completed the initial survey (T1) at the first outbreak phase of the pandemic, 148,343 students (response rate $33.7 \%$, valid questionnaire: $95.4 \%$ ) completed the secondwave survey (T2) at the COVID-19 remission stage (for epidemiologic assessment of the first two surveys, see Y Li, J Zhao, Z Ma, LS McReynolds, D Lin, Z Chen, T Wang, D Wang, Y Zhang, J Zhang, et al. [10]), 159,187 students (response rate 36.2\%, valid questionnaire: $95.7 \%$ ) completed the third-wave survey (T3) at normalization prevention stage, and 120,190 students (response rate $27.3 \%$, valid questionnaire: $97.5 \%$ ) completed the fourth-wave survey (T4) after returning to schools. Of the total participants, 13,462 students who participated in all four surveys were included in further analysis.

This study was approved by the Biomedical Ethics Committee, Southern Medical University, Guangzhou, China. Electronic informed consents were obtained online. All ethical concerns were maintained strictly.

\subsection{Procedures}

We prepared one common normative notice for all the 22 colleges, which mentioned the purpose, significance, deadline, and mode of participation in the online survey for all the four time periods. All students in the target universities were regarded as potential participants and were asked to voluntarily participate in the survey through the network platform (http://www.togx.cn/step_50.html). (For more details, see prior study Y Li, J Zhao, Z Ma, LS McReynolds, D Lin, Z Chen, T Wang, D Wang, Y Zhang, J Zhang, et al. [10]). We then matched the four data using the student ID to obtain the longitudinal sample data.

\subsection{Measurements}

\subsubsection{Demographic information}

The demographic information of the participants included age, gender (male or female), and college year (freshman, sophomore, junior, senior, and graduate).

\subsubsection{Family function}

The family function of the participants was assessed by Family APGAR [33] for T2-T4. Which had been translated into Chinese and have a good validation [34]. Sample items include "I am satisfied that I can turn to my family for help when something is troubling me," and "I am satisfied with the way my family talks over things with me and shares problems with me." The scale is rated on a 3-point Likert scale and consists of five items, with each item scored from 0 (never or rarely) to 2 (most or all of the time). The total score ranges from 0 to 10, and a score of 7-10 indicates a highly functional (HF) family, a score of 4-6 indicates a moderately dysfunctional family (MdF), and a score of $0-3$ indicates a severely dysfunctional (SdF) family. The Cronbach a was 0.89 at T2, 0.91 at T3, and 0.90 at T4 in this study.

\subsubsection{Coping style}

The coping style of the participants was assessed using Simplified Coping Style Questionnaire (SCSQ) [35] at T1. The SCSQ was developed by Chinese scholars and the has good validity and applicability[24]. The SCSQ is rated on a 4-point Likert scale and consists of 20 items, with each item scored from 0 (never) to 3 (very often). It consists of two dimensions: the active coping and the passive coping. Sample items of active coping include "trying to see things in as good a way as possible" and "identifying several different ways to solve problems." The passive coping dimension includes items such as "relieving troubles through smoking and drinking" and "fantasizing that some miracle may happen to change the status quo." The SCSQ score reflects the coping style preferences of participants, with a higher score indicating a higher possibility that the participant would adopt the relevant coping style. To identify the various coping styles theorized by N Ntoumanis, J Edmunds and JL Duda [27], in this study we used the standard score of active/passive coping to distinguish the participants into four group using method adapted from Fu et.al [24]. The standard score was achieved by Z-transformation of the mean and standard deviation of the active and negative coping styles of the entire sample of T1. If the $Z$ score of active coping $>0$ and the $Z$ score of passive coping $\leq 0$, it indicated that the individual generally adopted an active coping style. If the $Z$ score of active coping $\leq 0$ and the $Z$ score of passive coping $>0$, it indicated that the individual generally adopted a passive coping 
style. If the $Z$ scores of both active and passive copings $>0$, it indicated that the individual generally adopted a strong response coping style. If the $Z$ scores of both active and passive copings $\leq 0$, it indicated that the individual generally adopted a weak response coping style. The SCSQ is commonly used in China, and the Cronbach a coefficients for the two dimensions were 0.90 and 0.77 , respectively, in this study.

\subsubsection{Mental health issues}

Mental health issues reported by participants included depression and anxiety. Depression symptoms were assessed using Patient Health Questionnaire (PHQ-9) [36] on a 4-point scale ranging from 0 to 3. As validated in a Chinese population, a summed score of 7 indicates probable clinical depression [37]. The Cronbach a was 0.87 at T1, 0.90 at T2, 0.91 at T3, and 0.92 at $\mathrm{T} 4$.

Anxiety symptoms were measured using the Chinese version of Generalized Anxiety Disorder Scale (GAD-7) [38], which consists of 7 items rated on a 4-point scale from 0 to 3 . As validated in a Chinese population, a cutoff total score of 7 indicates clinical levels of anxiety [39]. The Cronbach a was 0.91 at T1, 0.92 at T2, 0.94 at T3, and 0.94 at T4.

\subsection{Covariates}

To control the association between family function and MHP for confounding, the following variables were adjusted: age group $(<18,18-19,20-21,22-23, \geq 24$ years), self-reported gender (male/female), self-reported mental health status before the outbreak, including self-reported prior mental health problems: "Have you ever been diagnosed with a mental illness. (yes/no)", and self-reported psychological counseling experience: "Have you received psychological counseling services from a professional (counselor, psychiatrist, etc.) in the past (yes/no)". The school type was initially coded as medical university, normal university, multi-faculty university, three-year normal college, and three-year vocational college, but was recoded to binary (university and three-year college) in order to reduce the parameters in the statistical models to meet convergence criteria.

\subsection{Statistical analysis}

We used generalized estimating equation (GEE) to quantify the change in MHP through 6 months from the beginning of the COVID-19 until schools reopened. GEE is often applied for longitudinal study with repeated measurements [40-42]. Logit link function was used to estimate odds ratio of different subgroups, the Newton-Raphson method was used to estimated parameter, Wald test was used to test main effect and interaction effect. The dependent variables were depression (PHQ-9 score $\geq 7$ ) and anxiety (GAD-7 score $\geq 7$ ) which transformed into dichotomous variables by cutoffs and measured at T1 though T4. The independent variables included time (four levels), family function (highly functional family, moderately functional family, and severely dysfunctional family) measured at T2-T4, coping style (active coping, passive coping, strong response coping, and weak response coping) measured at T1. The covariates include age, sex, health status, and school type. We used two models to check the associations. Model 1 was using time and family function as independent variables. Model 2 was using time, family function and coping style as independent variables. All covariates were controlled in both models.

All analyses were performed using Statistical Package for Social Sciences (SPSS) version 25.0.

\section{Results}

\subsection{Descriptive characteristics}

AOf the 13,462 participants included in this analysis, $74.8 \%$ were female participants of ages $16-29$ years $(M=19.68, S D=$ 1.38). Table 1 shows detailed sample characteristics, including gender, age, college year, university, and college type, ever received counseling for MHP from a professional, and prior MHP. 
Table 1

Sample characteristics $(N=13462)$

\begin{tabular}{|ll|}
\hline Variable & No. of students (\%) \\
\hline Gender & \\
\hline Male & $3387(25.2)$ \\
\hline Female & $10075(74.8)$ \\
\hline Age (years) & \\
\hline$<18$ & $918(6.82)$ \\
\hline $18-19$ & $7539(56.00)$ \\
\hline $20-21$ & $4426(32.88)$ \\
\hline $22-23$ & $405(3.01)$ \\
\hline$\geq 24$ & $174(1.29)$ \\
\hline University/college type & \\
\hline Medical university & $704(5.23)$ \\
\hline Normal university & $3421(25.41)$ \\
\hline Multifaculty university & $2571(19.10)$ \\
\hline Three-year normal college & $2087(15.50)$ \\
\hline Three-year vocational college & $4679(34.76)$ \\
\hline College year & $13381(99.40)$ \\
\hline Freshman & $1912(14.20)$ \\
\hline Sophomore & $143(1.07)$ \\
\hline Junior & \\
\hline Senior & \\
\hline Psychological counseling experience & \\
\hline Never & \\
\hline Yes & \\
\hline Prior mental health problems & \\
\hline No & \\
\hline Yes & \\
\hline
\end{tabular}

Table 2 shows sample sizes and percentage of each subgroup categorized by three independent variables: time, family function, and coping style. All subgroups had more than 100 participants. SdF was the smallest group (118 participants) with active coping style at T1 and T2, and HF was the largest group (2085 participants) with active coping style at T1 and T2. Most of the HF and MdF subgroups had around 1000 participants (795-2085 participants), whereas SdF subgroups had around 200 participants (118-400 participants). The sample sizes were enough to take next step in statistics. 
Sample Sizes of Subgroups

\begin{tabular}{|c|c|c|c|c|c|c|c|c|c|c|c|c|}
\hline & $\mathrm{T} 1$ & & & T2 & & & T3 & & & $\mathrm{T} 4$ & & \\
\hline & $\mathbf{N}$ & $\% *$ & & $\mathbf{N}$ & $\% *$ & & $\mathbf{N}$ & $\%($ & & $\mathbf{N}$ & $\%($ & \\
\hline $\mathrm{HF}$ & 6493 & 48.23 & & 6493 & 48.23 & & 5474 & 40.66 & & 6219 & 46.20 & \\
\hline $\begin{array}{l}\text { Active } \\
\text { coping }\end{array}$ & 2085 & 15.49 & (32.11) & 2085 & 15.49 & (32.11) & 1797 & 13.35 & (32.83) & 1949 & 14.48 & (31.34) \\
\hline $\begin{array}{l}\text { Passive } \\
\text { coping }\end{array}$ & 795 & 5.91 & (12.24) & 795 & 5.91 & (12.24) & 629 & 4.67 & (11.49) & 782 & 5.81 & (12.57) \\
\hline $\begin{array}{l}\text { Strong } \\
\text { response } \\
\text { coping }\end{array}$ & 1998 & 14.84 & (30.77) & 1998 & 14.84 & $(30.77)$ & 1714 & 12.73 & (31.31) & 1951 & 14.49 & (31.37) \\
\hline $\begin{array}{l}\text { Weak } \\
\text { response } \\
\text { coping }\end{array}$ & 1615 & 12.00 & $(24.87)$ & 1615 & 12.00 & $(24.87)$ & 1334 & 9.91 & (24.37) & 1537 & 11.42 & (24.71) \\
\hline MdF & 5911 & 43.91 & & 5911 & 43.91 & & 6674 & 49.58 & & 6096 & 45.28 & \\
\hline $\begin{array}{l}\text { Active } \\
\text { coping }\end{array}$ & 1021 & 7.58 & (17.27) & 1021 & 7.58 & (17.27) & 1255 & 9.32 & (18.80) & 1128 & 8.38 & (18.50) \\
\hline $\begin{array}{l}\text { Passive } \\
\text { coping }\end{array}$ & 1220 & 9.06 & $(20.64)$ & 1220 & 9.06 & $(20.64)$ & 1352 & 10.04 & $(20.26)$ & 1242 & 9.23 & (20.37) \\
\hline $\begin{array}{l}\text { Strong } \\
\text { response } \\
\text { coping }\end{array}$ & 1419 & 10.54 & $(24.01)$ & 1419 & 10.54 & $(24.01)$ & 1625 & 12.07 & (24.35) & 1439 & 10.69 & $(23.61)$ \\
\hline $\begin{array}{l}\text { Weak } \\
\text { response } \\
\text { coping }\end{array}$ & 2251 & 16.72 & (38.08) & 2251 & 16.72 & (38.08) & 2442 & 18.14 & (36.59) & 2287 & 16.99 & (37.52) \\
\hline SdF & 1058 & 7.86 & & 1058 & 7.86 & & 1314 & 9.76 & & 1147 & 8.52 & \\
\hline $\begin{array}{l}\text { Active } \\
\text { coping }\end{array}$ & 118 & 0.88 & (11.15) & 118 & 0.88 & (11.15) & 172 & 1.28 & (13.09) & 147 & 1.09 & (12.82) \\
\hline $\begin{array}{l}\text { Passive } \\
\text { coping }\end{array}$ & 327 & 2.43 & $(30.91)$ & 327 & 2.43 & $(30.91)$ & 361 & 2.68 & (27.47) & 318 & 2.36 & (27.72) \\
\hline $\begin{array}{l}\text { Strong } \\
\text { response } \\
\text { coping }\end{array}$ & 211 & 1.57 & (19.94) & 211 & 1.57 & (19.94) & 289 & 2.15 & (21.99) & 238 & 1.77 & (20.75) \\
\hline $\begin{array}{l}\text { Weak } \\
\text { response } \\
\text { coping }\end{array}$ & 402 & 2.99 & $(38.00)$ & 402 & 2.99 & $(38.00)$ & 492 & 3.65 & (37.44) & 444 & 3.30 & (38.71) \\
\hline
\end{tabular}

*Values within parentheses indicate within-group percentage.

Note: HF, highly functional family; MdF, moderately functional family; SdF, severely dysfunctional family.

\subsection{Longitudinal effect of family function on MHP}

Table 3 shows the main effects of time and family function for the incidence rates of MHP. All main effects are significant at $p<0.001$ level, which means MHP rates varied across the four-time point and different family functions. For the four-time survey periods, the highest incidence rate of depression is $43.53 \%(95 \% \mathrm{Cl}, 39.08-48.08)$ at T3 (i.e., when the students were at home quarantine), whereas the highest incidence rate of anxiety is $26.53 \%(95 \% \mathrm{Cl}, 22.64-30.82)$ at T4 (i.e., after students returned to schools). The incidence rates of MHP were lowest at T1, with 33.87\% (95\% Cl, 29.88-38.10) for depression and 
$17.45 \%(95 \% \mathrm{Cl}, 14.59-20.73)$ for anxiety. Among the family function groups, the SdF group had the highest incidence rate of both MHP, with depression at $53.80 \%(95 \% \mathrm{Cl}, 48.98-58.55)$ and anxiety at $30.20 \%(95 \% \mathrm{Cl}, 25.79-35.00)$.

Table 3

Main Effect of Time and Family Function with Marginal Incidence Rates of MHP

\begin{tabular}{|lll|}
\hline Subgroup & Depression \% $(95 \%$ Wald Cl) & Anxiety \% $(95 \%$ Wald Cl) \\
\hline Time & $33.87(29.88,38.10)$ & $17.45(14.59,20.73)$ \\
\hline T1 & $39.21(34.92,43.67)$ & $20.09(16.94,23.67)$ \\
\hline T2 & $43.53(39.08,48.08)$ & $22.50(19.05,26.37)$ \\
\hline T3 & $40.08(35.76,44.55)$ & $26.53(22.64,30.82)$ \\
\hline T4 & $193.68^{\star \star \star}$ & $195.74 * \star \star$ \\
\hline Main effect of time Wald $\chi^{2}$ & & $11.20(9.26,13.48)$ \\
\hline Family function & $22.46(19.43,25.81)$ & $27.21(23.29,31.52)$ \\
\hline HF & $44.01(39.62,48.50)$ & $30.20(25.79,35.00)$ \\
\hline MdF & $53.80(48.98,58.55)$ & $985.57 * \star \star$ \\
\hline SdF & $1509.21^{\star \star *}$ & \\
\hline Main effect of family function Wald $\chi^{2}$ & & \\
\hline
\end{tabular}

Note: MHP, mental health problems; HF, highly functional family; MdF, moderately functional family; SdF, severely dysfunctional family; $* \star *, p<0.001$

The pairwise comparisons of time (see Supplementary Table S1 available online) show that the incidence rates of depression rose during T1-T3 (all significant at $P<0.05$ level) and that the incidence rate at T4 is significantly lower than at T3 $(P<0.05)$ but not higher than at T2 $(P>0.05)$. As shown in Table 3 , the incidence rates of anxiety rose during T1-T4. The pairwise comparison of family function shows that the incidence rates of the HF group were lowest and of the SdF group were highest for all MHP (all differences are significant at $P<0.05$ level).

Table 4 shows the estimated marginal incidence rates of each MHP of each subgroup divide by time and family function. The table also includes interaction effect and simple effect of different MHP associated with time. Interaction effects are significant at $p<0.001$ level for both depression and anxiety, which means that the MHP of the participants with different family functions changed differently over time. 
Interaction Effects and Simple Effect of Time and Marginal Incidence Rates of MHP

\begin{tabular}{|c|c|c|c|c|}
\hline & \multicolumn{3}{|l|}{ Family Function } & \multirow{2}{*}{$\begin{array}{l}\text { Time } \times \text { Family Function } \\
\text { Wald } \chi^{2}\end{array}$} \\
\hline & HF & MdF & SdF & \\
\hline \multicolumn{5}{|l|}{$\begin{array}{l}\text { Depression \% (95 Wald } \\
\mathrm{Cl})\end{array}$} \\
\hline T1 & $\begin{array}{l}20.17(17.27 \\
23.41)\end{array}$ & $\begin{array}{l}36.04(31.88 \\
40.43)\end{array}$ & $\begin{array}{l}48.56(43.20 \\
53.95)\end{array}$ & 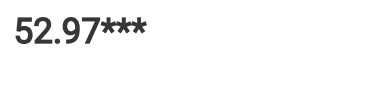 \\
\hline T2 & $\begin{array}{l}21.19(18.18 \\
24.54)\end{array}$ & $\begin{array}{l}42.74(38.28, \\
47.31)\end{array}$ & $\begin{array}{l}57.21(51.88 \\
62.37)\end{array}$ & \\
\hline T3 & $\begin{array}{l}26.19(22.68 \\
30.03)\end{array}$ & $\begin{array}{l}50.15(45.56 \\
54.73)\end{array}$ & $\begin{array}{l}56.20(51.01 \\
61.26)\end{array}$ & \\
\hline $\mathrm{T} 4$ & $\begin{array}{l}22.61(19.45 \\
26.11)\end{array}$ & $\begin{array}{l}47.44(42.88, \\
52.04)\end{array}$ & $\begin{array}{l}53.16(47.86 \\
58.39)\end{array}$ & \\
\hline $\begin{array}{l}\text { Simple effect of time } \\
\text { Wald } \chi^{2}\end{array}$ & $31.65^{\star \star \star}$ & $315.37^{\star \star \star *}$ & $53.68^{\star \star \star}$ & \\
\hline \multicolumn{5}{|l|}{ Anxiety \% (95 Wald Cl) } \\
\hline T1 & $9.86(8.00,12.01)$ & $\begin{array}{l}19.43(16.26, \\
23.05)\end{array}$ & $\begin{array}{l}26.45(21.84 \\
31.64)\end{array}$ & $51.25 * \star *$ \\
\hline T2 & $\begin{array}{l}10.02(8.17 \\
12.24)\end{array}$ & $\begin{array}{l}24.93(21.15, \\
29.12)\end{array}$ & $\begin{array}{l}30.06(25.20 \\
35.43)\end{array}$ & \\
\hline T3 & $\begin{array}{l}10.99(8.97 \\
13.40)\end{array}$ & $\begin{array}{l}31.13(26.79 \\
35.82)\end{array}$ & $\begin{array}{l}30.48(25.67 \\
35.75)\end{array}$ & \\
\hline $\mathrm{T} 4$ & $\begin{array}{l}14.44(11.92, \\
17.39)\end{array}$ & $\begin{array}{l}35.05(30.41 \\
39.99)\end{array}$ & $\begin{array}{l}34.06(28.88 \\
39.66)\end{array}$ & \\
\hline $\begin{array}{l}\text { Simple effect of time } \\
\text { Wald } \chi^{2}\end{array}$ & $14.43^{\star \star}$ & $220.22 * \star \star$ & 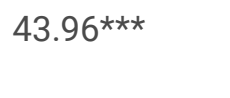 & \\
\hline
\end{tabular}

Note: MHP, mental health problems; HF, highly functional family; MdF, moderately functional family; SdF, severely dysfunctional family. ${ }^{*}, p<0.01 ; * \star *, p<0.001$

The pairwise comparisons of the incidence rates of MHP for each family function group with significant simple effect at different time points (see Supplementary Table S2 available online) show (high and low means significant at $P<0.05$ level) that for the HF group the incidence rates of depression do not rise until T3, which is higher than other time, and that T4 is lower than T3 and higher than T1 but not T2. The incidence rates of anxiety rise only at T4, and there is no statistically significant difference between $\mathrm{T} 1$ and $\mathrm{T} 3$.

In the MdF group, the incidence rates of depression have significant difference between each time, meaning that the growth tendency stops at T4, but is still higher than at T2. The incidence rates of anxiety also have significant difference between each time, meaning it keeps growing from T2 to T4.

In the SdF group, the incidence rates of depression are higher at T2 and T3 than at T1 and other differences are not significant. The incidence rates of anxiety are higher at $\mathrm{T} 2-\mathrm{T} 4$ than at $\mathrm{T} 1$, and $\mathrm{T} 4$ is higher than $\mathrm{T} 2$.

To demonstrate the odds ratio of different subgroups and the change in pattern through time, we carried out an adjusted multivariance logistic regression analysis by EEG, using T1-HF group as reference group, covariates mentioned in Section 2.4 were controlled in the analyses.. Figure 1 shows the forest plot of adjusted odds ratio (AOR) and $95 \% \mathrm{Cl}$ of each subgroup at the two MHP. 


\subsection{Longitudinal moderating effect of coping style to family function on MHP}

The three-way interaction between time, family function and coping style on depression and anxiety incident rate are calculated, Wald $\chi^{2}$ and are 862.09, $p<0.001$ and 583.29, $p<0.001$, respectively. The simple effects of time were also calculated (see Table 5 for simple effect of time by each subgroup). Except HF group with passive coping style on anxiety, SdF group with passive and weak response coping on both MPH do not have significant simple effect of time, other subgroups' MHP are associated with time significantly.

Table 5

Interaction Effect and Simple Effect of Time (Wald $\left.\chi^{2}\right)$

\begin{tabular}{|llllllll|}
\hline Family Function & HF & & MdF & \multicolumn{3}{c|}{ SdF } \\
\hline MHP & & Depression & Anxiety & Depression & Anxiety & Depression & Anxiety \\
\hline \multirow{2}{*}{ Coping Style } & Active & $44.9^{* * *}$ & $17.8^{* * *}$ & $91.22^{* * *}$ & $70.88^{* * *}$ & $39.5^{* * *}$ & $13.21^{* * *}$ \\
\cline { 2 - 8 } & Passive & $11.2^{*}$ & 7.8 & $37.42^{* * *}$ & $64.48^{* * *}$ & 4.59 & 5.14 \\
\cline { 2 - 8 } & Strong response & $10.04^{*}$ & $15.71^{* * *}$ & $98.39^{* * *}$ & $116.83^{* * *}$ & $16.18^{* * *}$ & $8.39^{*}$ \\
\cline { 2 - 8 } & Weak response & $18.8^{* * *}$ & $20.27^{* * *}$ & $132.24^{* * *}$ & $99.15^{* * *}$ & 5.01 & 1.82 \\
\hline
\end{tabular}

Note: $*, p<0.05 ; * \star, p<0.01 ; * \star \star, p<0.001$

Note: HF, highly functional family; MdF, moderately functional family; SdF, severely dysfunctional family.

To demonstrate the odds ratio of different subgroups and the change in pattern through time, an adjusted multivariance logistic regression analysis by EEG was carried out using T1-HF group with active coping style as reference. Figure 2 shows the forest plot of AOR and $95 \% \mathrm{Cl}$ of each subgroup at the two MHP.

To present the significant result clearly, in this paper we only describe the differences between T1 and T3 and between T3 and T4 because these two survey pairs show the differences of the 4-month home quarantine and before and after schools reopened (rise and down means significant at $P<0.05$ level level). For the HF group, the incidence rates for depression rise between T3 and T1, except for passive coping subgroup. However, at T3, the AOR of the HF group is 8.21, of the active coping subgroup is 2.19 , of the strong response coping subgroup is 4.39 , and of the weak response coping subgroup is 3.49 ; also note that the risk of passive coping subgroup is high throughout the quarantine period. After schools resumed, the incidence rates of MHP of all subgroups were low, except for weak response subgroup, and the incidence rates of the passive coping subgroup were down by $7.86 \%$ and its AOR went down to 5.89 . The incidence rates for anxiety rise between T3 and T1 for active and weak response coping subgroups. At T3, the AORs of active and weak response coping subgroups were 1.44 and 2.86, respectively, whereas the AOR of passive coping subgroup was 5.68. After students returned to school, the incidence rates of all subgroups were higher, and the incidence rate of passive coping subgroup rose to $5.57 \%$ and AOR was 7.96 .

For the MdF group, all four MHP incidence rates rose during T1-T3. For active, passive, strong response, and weak response subgroups, the incidence rates of depression rise $17.49 \%, 10.18 \%, 15.74 \%$, and $14.40 \%$, respectively, and the AORs rise from 2.36 to $5.94,11.38$ to $17.24,7.00$ to 13.24 , and 4.95 to 9.14 , respectively. For passive and strong response coping style subgroups, the incidence rates fall at T3-T4 by $4.34 \%$ and $3.90 \%$, respectively, and the AORs rise to 14.4 and 11.32 , respectively. For active, passive, strong response, and weak response subgroups, the incidence rates of anxiety rise $8.79 \%$, $10.76 \%, 16.65 \%$, and $10.13 \%$, respectively, and the AORs rise from 2.35 to $5.3,10.57$ to $17.04,6.30$ to 14.62 , and 5.17 to 9.40 , respectively. MHP incidence rise up at T3 to T4 for active and weak response coping style group.

For the SdF group, a result worth noticing is that the incidence rates of MHP did not change after students rejoined school. The incidence rates of depression rise $29.76 \%$ and $9.86 \%$ from T1 to T3 for active and strong response coping styles, and the 
AOR rise from 1.99 to 8.97 for active coping style and from 8.8 to 13.10 for strong response coping style. The AOR of depression for passive coping rise from 18.27 at T1 to 23.58 at T3, and the AOR for weak response coping style rise from 9.08 at T1 to 10.67 at T3. Incidence rate of depression has no significant change after students returned to school. For active coping subgroup, the incidence rates of anxiety rise $13.43 \%$ from T1 to T3 and the AOR changes from 1.93 to 6.55 . Other subgroups have no significant change from T1 to T3. The AOR of passive coping subgroup are 14.33 at T1 and 17.3 at T3. For all coping style subgroups, there was no significant change after students returned to school.

\section{Discussion}

In this longitudinal study, we analyzed the tangling interaction effect of family function and coping styles with MHP during and after the stay-at-home period of February to October 2020. College students across China were required to take online courses at home for a semester and returned to school to take in-person classes but wear a mask and keep social distance, it was an opportunity to study the relationship between these variables.

We found that the incidence rates of depression rose from $33.87 \%(95 \% \mathrm{Cl}, 29.88 \%-38.10 \%)$ to $43.53 \%(95 \% \mathrm{Cl}, 39.08 \%$ $-48.08 \%)$ during the stay-at-home period and dropped to $40.08 \%(95 \% \mathrm{Cl}, 35.76 \%-44.55 \%)$ after students returned to school. The incidence rates of anxiety rose from $17.45 \%(95 \% \mathrm{Cl}, 14.59 \%-20.73 \%)$ to $22.50 \%(95 \% \mathrm{Cl}, 16.94 \%-23.67 \%)$ during the stay-at-home period and kept rising to $26.53 \%(95 \% \mathrm{Cl}, 22.64 \%-30.82 \%)$ after students returned to school. Our results are in line with the recent studies of M Daly, AR Sutin and E Robinson [8], who state that pronounced and prolonged deterioration in mental health of people occurred during the COVID-19 crisis in UK, and [12]the pandemic has had a negative impact on the mental health of general population in Spain and the mental health of people still does not seem to be at pre-crisis levels even after the country returned to new normality [5]. The prolonged deterioration in mental health after the break out of COVID-19 also has been observed in college students at other Asian countries, such as [46]Japan [43], Korea [44], India [45], [48]Pakistan[46], and Bangladeshi [47]. Because of these countries shared similar collectivist cultures such as emphasis on family relationships, family function may have an even more severe impact on mental health during the pandemic compared with individualistic cultures.

The result of interaction effect of family function and time with MHP shows different family function group changes in varying pattern though time: the incidence rates of MHP rose during the stay-at-home period in all family groups, which indicates that none of the family function could not protect the mental health of students from the impact of the pandemic. After students returned to school at T4, the direct influence of family function lessened and interaction with friends and classmates became normal, which partly explains the reduction in the incidence rates of depression at T4 in HF and MdF groups. However, there was no change in the incidence rates of depression in the SdF group, which indicates a prolonged negative affinity of dysfunctional family function to depression. According to X Wang, S Hegde, C Son, B Keller, A Smith and F Sasangohar [48], after most universities and colleges shifted to online study mode during March to June 2020, the academicrelated concerns due to pandemic situation have increased, which explains why in our study the incidence rates of anxiety in the HF group increased during T3-T4.

After taking coping styles into consideration, the variance of each subgroup began to emerge. Interestingly, for the passive coping style with HF subgroup, unlike with other subgroups, the incidence rates of MHP tended to reduce during T1-T3 and rise during T3-T4, showing a stronger protective effect of family. However, for the active coping style with SdF subgroup, the incidence rates of MHP tended to rise during T1-T3 and reduce during T3-T4, showing a stronger protective effect of coping style. Additionally, passive coping style with dysfunctional family subgroup had the highest incidence rates of all MHP during T1-T4, indicating that the risk of having MHP was 10 times higher than active coping style with HF subgroup. These results corroborate the findings of previous studies in this field [24, 29].

There are very few studies that consider the relationship between MHP and strong response or weak response coping style. Most of the previous studies using SCSQ have divided participants into only two categories and used the differential value between the standard score of active coping minus the standard score of passive coping to determine the tendency of 
individual coping styles. If the differential value was greater than 0 , it indicated that the individual generally adopted an active coping style and vice versa [24]. This grouping is arbitrary because the two scores may be very close and an individual may use many coping strategies to overcome difficulties, and therefore we used the method mentioned in Section 2.3.3 to differentiate among coping styles. This gave us a chance to investigate the changing pattern of those who reacted strongly to pull through the pandemic and those who reacted weakly. The result is interesting: both groups have lower incidence rates of MHP than the passive coping group, which can be explained by coping styles theorized by RS Lazarus and S Folkman [28]. As explained by N Ntoumanis, J Edmunds and JL Duda [26] in their integrated model of stress, coping, and motivation, a strong response coping style is aroused by threat appraisals of the stressor, while a weak response coping style is aroused by benign appraisals of the stressor. However, the change in pattern of these two group in different family function for depression and anxiety are alike and their AOR did not change as drastically as the that of passive coping style, which could be aroused from harm-loss appraisals. According to N Ntoumanis, J Edmunds and JL Duda [26] N Ntoumanis, J Edmunds and JL Duda [27], N Ntoumanis, J Edmunds and JL Duda [28]effective coping requires a fit between social context, situational appraisals, and choice of coping responses. When variations in actual coping behavior do not result in a "fit" between situational factors and actual coping efforts, one may increase their emotional arousal to a level exceeding that which they can tolerate [49], the current pandemic has not had serious losses for most student, so harm-loss appraisal is an inappropriate response, when the time pass by, the negative effects of inappropriate appraisal will get stronger, this can explain why MHP shows a more stable pattern in the active, strong/weak response coping style group compared with passive coping style.

These findings suggest that college management staff need to adapt in several ways in the future. First, when the epidemic eases or home isolation over a period of time, let students choose whether come back to school or keep staying at home, especially students with SdF. Second, to reduce students' harm-loss appraisal of the epidemic situation, correct knowledge of the situation needs to be promoted timely. Third, low-intensity intervention such as web-based consultation service or telephone hotline is recommended.

\subsection{Strengths and Limitations}

This study has several advantages: we prospectively followed up a large sample of college students in multiple waves from the first month of the COVID-19 pandemic until the reopening of schools. COVID-19-related MHP depressive symptoms and anxiety were repeatedly assessed with well-established scales. Moreover, the coping style of participants were divided into four categories to get more detailed result. However, our study is not without limitations. First, our sample was collected via convenience sampling methods and may not be fully representative of the general population of college students in China. For example, females constituted a relatively large proportion of the sample, which might limit the generalizability of our results the reasons for this may because females are more responsive and cooperative in the context of the questionnaire survey $[50,51]$. Second, current mental health disorders were collected by single self-reported items, but no structured or standardized clinical diagnostic interview was used to validate the diagnoses according to DSM or ICD criteria which may be affected by recall bias. Third, the coping style was measured at T1 and family function was measured from T2 because the development of the epidemic was not clear in the initial few months. Although SCSQ has high test-retest reliability (0.89) [35], a lack of repeated measurements could lead to bias in estimates.

\section{Conclusion}

The COVID-19 pandemic has had prolonged negative effects on the mental health of college students in China. Even students with HF or active coping style had a deterioration in the mental health. The negative influence of dysfunctional family function does not cease affecting the mental health of students even after schools restarted. MHP show a more stable pattern for the active, strong/weak response coping style group compared with passive coping style. These findings contribute to a greater understanding of the interaction of family function and coping style with mental health of college students during the COVID-19 pandemic. It is now a well-established fact that pandemic-induced mental health issues have become a big global issue. It is thus the need of the hour that greater attention be paid to students with dysfunctional family function and help them cultivate active coping styles. Let students choose whether come back to school or keep staying at home and

Page $12 / 17$ 
disseminating correct information about the pandemic. Low-intensity intervention such as web-based consultation service or telephone hotline is recommended.

\section{Declarations}

Ethics approval and consent to participate

This study was approved by the appropriate institutional research and ethics committee of Southern Medical University. Electronic informed consents were obtained online. All participants were informed that they could withdraw from the study at any point of time. This study was conducted in accordance with the Declaration of Helsinki.

Consent for publication

Not applicable

Availability of data and materials

The datasets used and/or analysed during the current study available from the corresponding author on reasonable request.

Competing interests

The authors declare that they have no competing interests

Funding

None

Authors' contributions

L.L: data analysis, wrote the main manuscript text. J.C. and S.L.: reviewing and editing. W.W, X.P. and C.C.: revising the manuscript. A.H. and X.W: data analysis. J.Z: Supervision, reviewing and editing. All authors read and approved the final manuscript.

Acknowledgements

Not applicable

\section{References}

1. Santomauro DF, Mantilla Herrera AM, Shadid J, Zheng P, Ashbaugh C, Pigott DM, Abbafati C, Adolph C, Amlag JO, Aravkin AY et al: Global prevalence and burden of depressive and anxiety disorders in 204 countries and territories in 2020 due to the COVID-19 pandemic. The Lancet 2021, 398(10312):1700-1712.

2. Fountoulakis KN, Karakatsoulis G, Abraham S, Adorjan K, Ahmed HU, Alarcón RD, Arai K, Auwal SS, Berk M, Bjedov S et al: Results of the COVID-19 mental health international for the general population (COMET-G) study. European Neuropsychopharmacology 2022, 54:21-40-40.

3. Holmes EA, O'Connor RC, Perry VH, Tracey I, Wessely S, Arseneault L, Ballard C, Christensen H, Cohen Silver R, Everall I et al: Multidisciplinary research priorities for the COVID-19 pandemic: a call for action for mental health science. The Lancet Psychiatry 2020, 7(6):547-560.

4. Wang Z-H, Yang H-L, Yang Y-Q, Liu D, Li Z-H, Zhang X-R, Zhang Y-J, Shen D, Chen P-L, Song W-Q et al: Prevalence of anxiety and depression symptom, and the demands for psychological knowledge and interventions in college students during COVID-19 epidemic: A large cross-sectional study. Journal of Affective Disorders 2020, 275:188-193. 
5. González-Sanguino C, Ausín B, Castellanos MA, Saiz J, Muñoz M: Mental health consequences of the Covid-19 outbreak in Spain. A longitudinal study of the alarm situation and return to the new normality. Progress in Neuro-

Psychopharmacology and Biological Psychiatry 2021, 107:110219.

6. Qiu J, Shen B, Zhao M, Wang Z, Xie B, Xu Y: A nationwide survey of psychological distress among Chinese people in the COVID-19 epidemic: implications and policy recommendations. General Psychiatry 2020, 33(2):e100213.

7. Lau JTF, Yang X, Tsui HY, Pang E, Wing YK: Positive mental health-related impacts of the SARS epidemic on the general public in Hong Kong and their associations with other negative impacts. Journal of Infection 2006, 53(2):114-124.

8. Daly M, Sutin AR, Robinson E: Longitudinal changes in mental health and the COVID-19 pandemic: evidence from the UK Household Longitudinal Study. Psychol Med 2020:1-10.

9. Wang C, Pan R, Wan X, Tan Y, Xu L, Mclntyre RS, Choo FN, Tran B, Ho R, Sharma VK et al: A longitudinal study on the mental health of general population during the COVID-19 epidemic in China. Brain, Behavior, and Immunity 2020, 87:4048.

10. Li Y, Zhao J, Ma Z, McReynolds LS, Lin D, Chen Z, Wang T, Wang D, Zhang Y, Zhang J et al: Mental Health Among College Students During the COVID-19 Pandemic in China: A 2-Wave Longitudinal Survey. Journal of Affective Disorders 2021, 281:597-604.

11. Shanahan L, Steinhoff A, Bechtiger L, Murray AL, Nivette A, Hepp U, Ribeaud D, Eisner M: Emotional distress in young adults during the COVID-19 pandemic: evidence of risk and resilience from a longitudinal cohort study. Psychological medicine 2020:1-10.

12. Chirico F, Ferrari G, Nucera G, Szarpak L, Crescenzo P, Ilesanmi O: Prevalence of anxiety, depression, burnout syndrome, and mental health disorders among healthcare workers during the COVID-19 pandemic: a rapid umbrella review of systematic reviews. J Health Soc Sci 2021, 6(2):209-220.

13. Grolli RE, Mingoti MED, Bertollo AG, Luzardo AR, Quevedo J, Réus GZ, Ignácio ZM: Impact of COVID-19 in the Mental Health in Elderly: Psychological and Biological Updates. Molecular Neurobiology 2021, 58(5):1905-1916.

14. Peng X, Liang S, Liu L, Cai C, Chen J, Huang A, Wang X, Zhao J: Prevalence and associated factors of depression, anxiety and suicidality among Chinese high school E-learning students during the COVID-19 lockdown. Current Psychology 2022.

15. Garber J: Chap. 12 - Depression and the Family*. In: Psychopathology and the Family. edn. Edited by Hudson JL, Rapee RM. Oxford: Elsevier; 2005: 225-280.

16. Downey G, Coyne JC: Children of depressed parents: an integrative review. Psychol Bull 1990, 108(1):50-76.

17. LaRoche C: Children of Parents with Major Affective Disorders: A Review of the Past 5 Years. Psychiatric Clinics of North America 1989, 12(4):919-932.

18. Zhang H: The Influence of the Ongoing COVID-19 Pandemic on Family Violence in China. Journal of Family Violence 2020.

19. Cao X, Jiang X, Li X, Hui Lo M-cJ, Li R: Family Functioning and Its Predictors among Disaster Bereaved Individuals in China: Eighteen Months after the Wenchuan Earthquake. PLOS ONE 2013, 8(4):e60738.

20. Cheng Y, Zhang L, Wang F, Zhang P, Ye B, Liang Y: The effects of family structure and function on mental health during China's transition: a cross-sectional analysis. BMC Family Practice 2017, 18(1):59.

21. Sprusińska E: The Family APGAR Index: study on relationship between family function, social support, global stress and mental health perception in women. International journal of occupational medicine and environmental health 1994, 7(1):23-32.

22. Pan Y, Yang Z, Han X, Qi S: Family functioning and mental health among secondary vocational students during the COVID-19 epidemic: A moderated mediation model. Personality and Individual Differences 2021, 171:110490.

23. Yu H, Li M, Li Z, Xiang W, Yuan Y, Liu Y, Li Z, Xiong Z: Coping style, social support and psychological distress in the general Chinese population in the early stages of the COVID-19 epidemic. BMC Psychiatry 2020, 20(1):426.

24. Fu W, Wang C, Zou L, Guo Y, Lu Z, Yan S, Mao J: Psychological health, sleep quality, and coping styles to stress facing the COVID-19 in Wuhan, China. Translational psychiatry 2020, 10(1):225. 
25. Noorbakhsh SN, Besharat MA, Zarei J: Emotional intelligence and coping styles with stress. Procedia - Social and Behavioral Sciences 2010, 5:818-822.

26. Ntoumanis N, Edmunds J, Duda JL: Understanding the coping process from a self-determination theory perspective. British Journal of Health Psychology 2009, 14(2):249-260.

27. Ntoumanis N, Edmunds J, Duda JL: Understanding the coping process from a self-determination theory perspective. British journal of health psychology 2009, 14(Pt 2):249-260.

28. Lazarus RS, Folkman S: Stress, appraisal, and coping: Springer publishing company; 1984.

29. Ye Z, Yang X, Zeng C, Wang Y, Shen Z, Li X, Lin D: Resilience, Social Support, and Coping as Mediators between COVID-19related Stressful Experiences and Acute Stress Disorder among College Students in China. Applied Psychology: Health and Well-Being 2020, 12(4):1074-1094.

30. Wang C, Havewala M, Zhu Q: COVID-19 stressful life events and mental health: Personality and coping styles as moderators. Journal of American College Health 2022:1-10.

31. Chirico F: Spirituality to cope with COVID-19 pandemic, climate change and future global challenges. J Health Soc Sci 2021, 6(2):151-158.

32. Ma Z, Zhao J, Li Y, Chen D, Wang T, Zhang Z, Chen Z, Yu Q, Jiang J, Fan F et al: Mental health problems and correlates among 746217 college students during the coronavirus disease 2019 outbreak in China. Epidemiology and Psychiatric Sciences 2020, 29:e181.

33. Smilkstein G, Ashworth C, Montano D: Validity and reliability of the family APGAR as a test of family function. The Journal of family practice 1982, 15(2):303-311.

34. Lu F, Zeng G, Liu SN, Zhong TL, Zhan ZQ: A Study on Validity and Reliability of the Family APGAR. Chinese Journal of Public Health 1999, 15(11):2.

35. Xie Y: Reliability and validity of the simplified Coping Style Questionnaire.. Chinese Journal of Clinical Psychology 1998, 6(2):114-115.

36. Kroenke K, Spitzer RL, Williams JBW: The PHQ-9: validity of a brief depression severity measure. journal of general internal medicine 2001, 16(9):606-613.

37. Wang W, Bian Q, Zhao Y, Li X, Wang W, Du J, Zhang G, Zhou Q, Zhao M: Reliability and validity of the Chinese version of the Patient Health Questionnaire (PHQ-9) in the general population. Gen Hosp Psychiatry 2014, 36(5):539-544.

38. Spitzer RL, Kroenke K, Williams JB, Lowe B: A Brief Measure for Assessing Generalized Anxiety Disorder: The GAD-7. jama 2006, 166(10).

39. Tong X, An D, McGonigal A, Park SP, Zhou D: Validation of the Generalized Anxiety Disorder-7 (GAD-7) among Chinese people with epilepsy. Epilepsy research 2016, 120:31-36.

40. Liang K-Y, Zeger SL: Longitudinal data analysis using generalized linear models. Biometrika 1986, 73(1):13-22.

41. Zeger SL, Liang KY: Longitudinal data analysis for discrete and continuous outcomes. Biometrics 1986, 42(1):121-130.

42. Ziegler A, Vens M: Generalized Estimating Equations. Methods Inf Med 2010, 49(05):421-425.

43. Tahara M, Mashizume Y, Takahashi K: Mental Health Crisis and Stress Coping among Healthcare College Students Momentarily Displaced from Their Campus Community Because of COVID-19 Restrictions in Japan. International Journal of Environmental Research and Public Health 2021, 18(14):7245.

44. Yun J-Y, Kim JW, Myung SJ, Yoon HB, Moon SH, Ryu H, Yim J-J: Impact of COVID-19 on Lifestyle, Personal Attitudes, and Mental Health Among Korean Medical Students: Network Analysis of Associated Patterns. Frontiers in Psychiatry 2021, 12.

45. Verma K: The mental health impact of the COVID-19 epidemic on college students in India. Asian Journal of Psychiatry 2020, 53:102398.

46. Anser MK, Sharif M, Khan MA, Nassani AA, Zaman K, Abro MMQ, Kabbani A: Demographic, psychological, and environmental factors affecting student's health during the COVID-19 pandemic: on the rocks. Environmental Science and 
Pollution Research 2021.

47. Sultana MS, Khan AH, Hossain S, Hasan MT: Mental health difficulties in students with suspected COVID-19 symptoms and students without suspected COVID-19 symptoms: A cross-sectional comparative study during the COVID-19 pandemic. Children and Youth Services Review 2021, 128:106137.

48. Wang X, Hegde S, Son C, Keller B, Smith A, Sasangohar F: Investigating Mental Health of US College Students During the COVID-19 Pandemic: Cross-Sectional Survey Study. Journal of medical Internet research 2020, 22(9):e22817.

49. Kohlmann C-W: Rigid and flexible modes of coping: Related to coping style? Anxiety, Stress, \& Coping 1993, 6(2):107123.

50. Peshkovskaya A, Babkina T, Myagkov M: Social context reveals gender differences in cooperative behavior. Journal of Bioeconomics 2018, 20(2):213-225-225.

51. Eckel C, de Oliveira ACM, Grossman PJ: Gender and Negotiation in the Small: Are Women (Perceived to Be) More Cooperative than Men? Negotiation Journal 2008, 24(4):429-445.

\section{Figures}
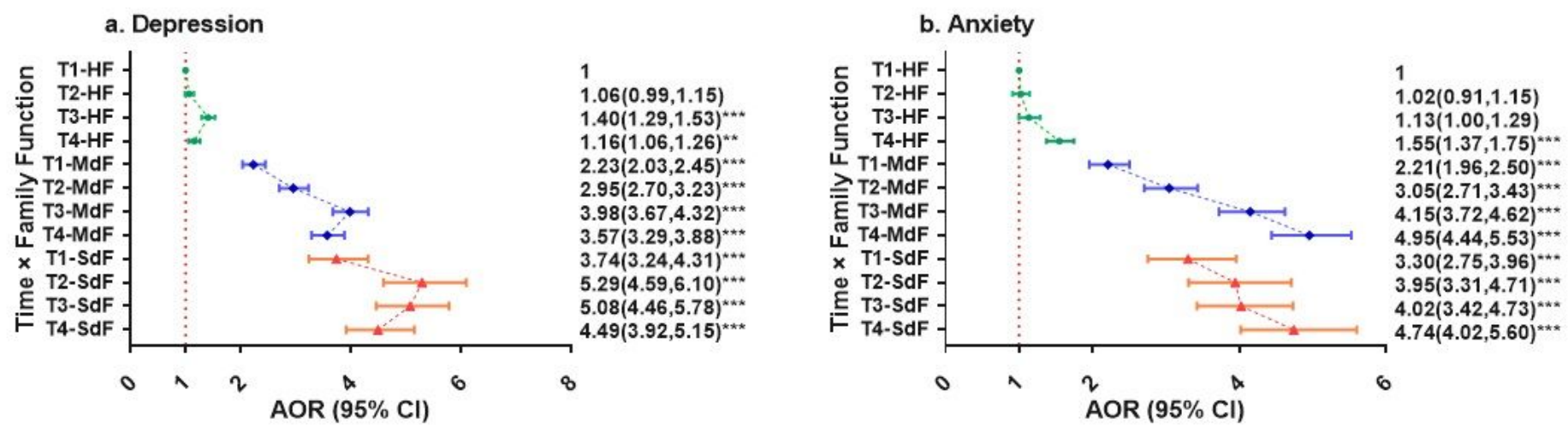

Figure 1

Forest plot showing adjusted multivariance logistic regression analysis: time $\times$ family function. HF, highly functional family; MdF, moderately dysfunctional family; SdF, severely dysfunctional family; AOR, adjusted odds ratio; ${ }^{\star \star} p<0.01 ;{ }^{* \star} p<0.001$. AOR was adjusted for age, gender, mental health status before the outbreak of the pandemic, and school type. 


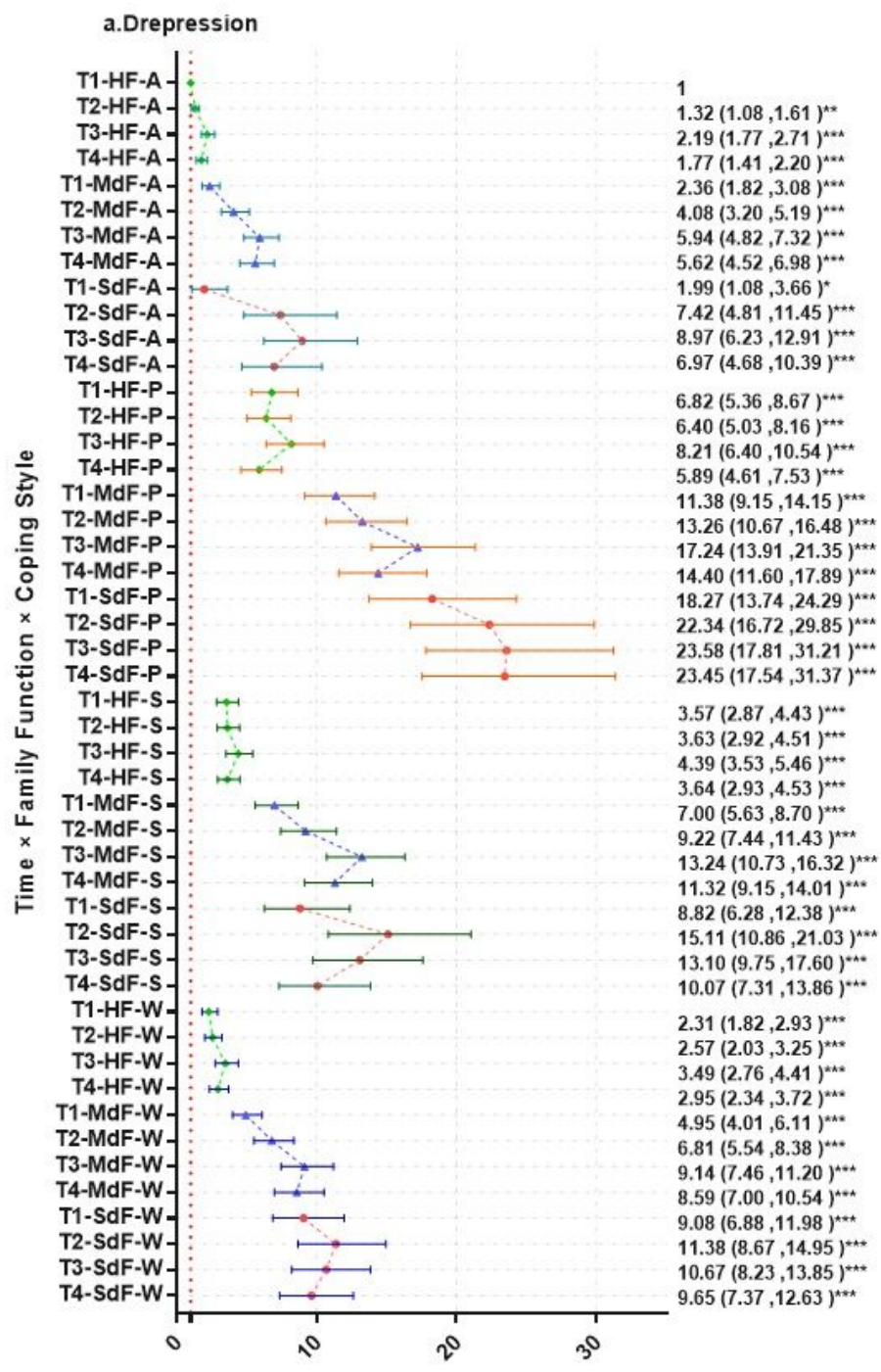

AOR $(95 \% \mathrm{Cl})$

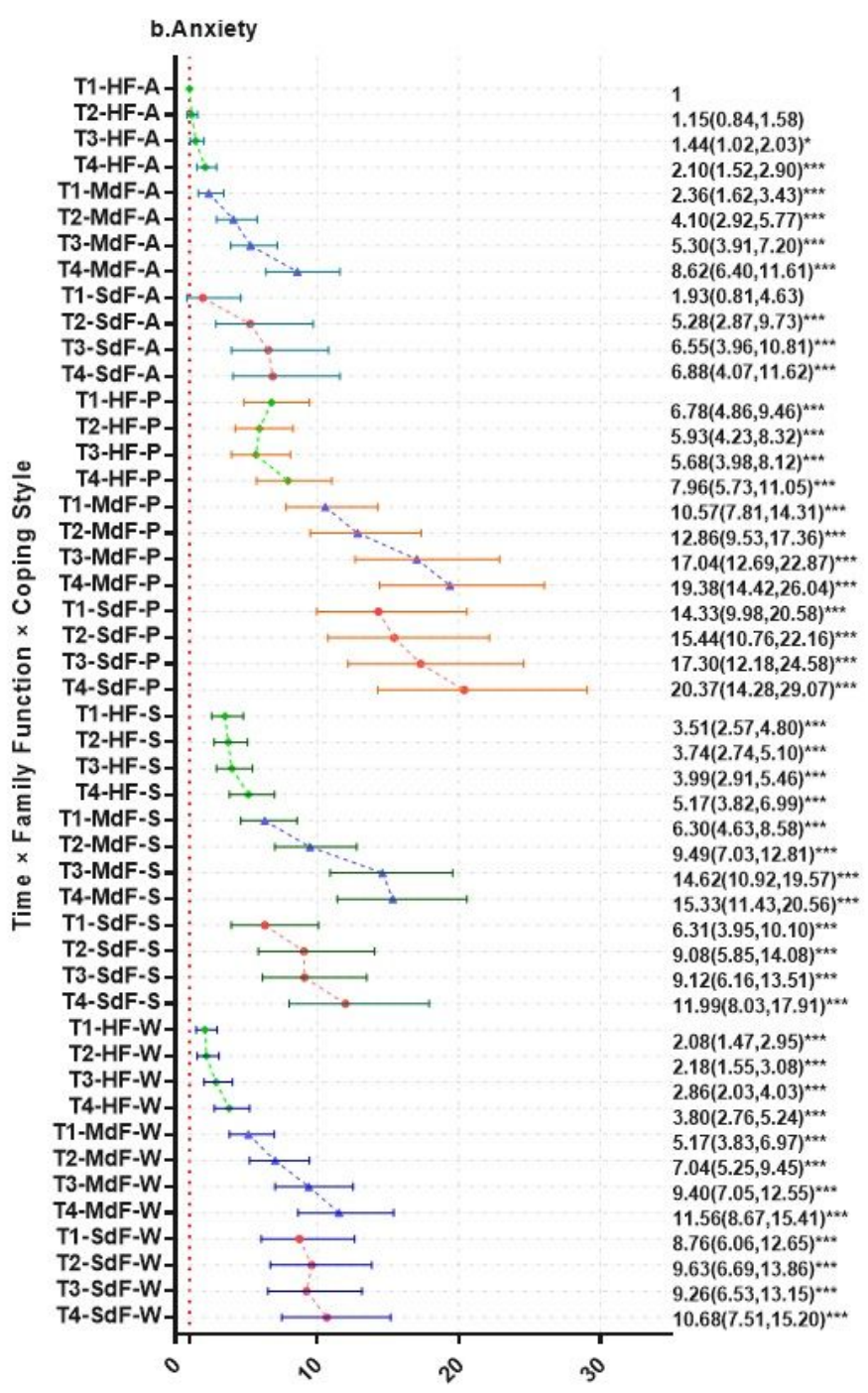

AOR $(95 \% \mathrm{Cl})$

\section{Figure 2}

Forest plot showing adjusted multivariance logistic regression analysis: time $\times$ family function $\times$ Coping Style. HF, highly functional family; MdF, moderately dysfunctional family; SdF, severely dysfunctional family; $A$, active coping style; $P$, passive coping style; $\mathrm{S}$, strong response coping style; W, weak response coping style; AOR, adjusted odds ratio; ${ }^{\star \star} p<0.01$; ${ }^{\star \star \star} p<$ 0.001. AOR was adjusted for age, gender, mental health status before the outbreak of the pandemic, and school type.

\section{Supplementary Files}

This is a list of supplementary files associated with this preprint. Click to download.

- SupplementalTables.docx 